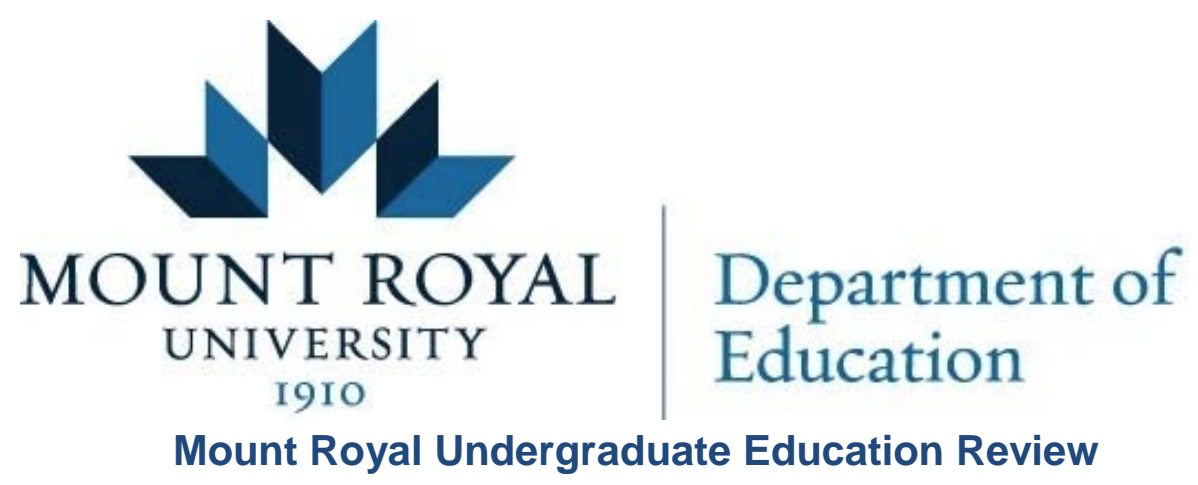

Volume 1(3)

Fall 2015

\title{
Strengthening mathematical problem solving skills: Through the use of digital technology
}

Jasdeep Ubhi, Mount Royal University

\section{Link to Digital Story}

\begin{abstract}
In this study I propose to explore how digital technology can strengthen problem-solving skills in mathematics. To address this I composed a literature review on scholarly sources. I also conducted an online survey consisting of 20 participants from Mount Royal University. Lastly, I interviewed a professional and professor in the mathematics field, Dr. Pamini Thangararah, to draw upon her experience and views on problem solving in mathematics using technology. My data determines that digital technology is a tool utilized to problem solve in mathematics. According to my findings, technology is preferred to be used in math and to help problem solve. The significance to this research study is to identify whether students can use digital technology for math and to encourage high levels of problem solving skills. It is important for elementary teachers to utilize technology as a resource to enhance their students understanding of mathematics, thus leading to mathematical success.
\end{abstract}




\section{Introduction}

Technology is an amazing resource and as it continues to advance, we begin to rely on it to make our personal lives easier. Even though we are able to use devices such as cell phones and tablets throughout our daily lives, it can be challenging to incorporate it in education and academic. Technology for educational use is diverse and what particularly interests me is the use of technology in Mathematics. I have an immense passion for math and I find that it is uncommon to relate to others that enjoy it as much as I do. It makes me wonder what experience discouraged them throughout their journey of learning math. However, my goal is to change this perspective. I think that there are many thought-provoking and engaging subjects within math, especially to get students to acknowledge the wonders of it. From my previous experience in schools and interactions with students, I noticed a lack of interest towards math. I began to observe further and pinpoint the concepts that students struggled with that made them dislike math.

Based on my observations, students mainly struggle with mathematical problem solving. When problem solving in mathematics I saw that students were not able to identify important information and use that information to determine to an answer. In today’s society children are learning how to use technology from young ages. From games to social media, it is evident that they enjoy using technology. If we can incorporate technology and math maybe it can help reinforce student mathematical problem-solving skills. Therefore, how can we efficiently incorporate digital technology in mathematics to help develop and strengthen problem-solving skills?

The indicated question is important to me because it will help students solve the issues they are having with mathematics, making it enjoyable to learn. This will help my future practice 
because it will allow me to learn strategies to integrate technology into mathematics and strengthen problem-solving skills. With the assistance of technology, my aim is to build eagerness towards math, so one day I can share my passion for math with others.

\section{Background}

In order to investigate my topic, It is important to build on prior research related to how digital technology helps strengthen problem solving skills in elementary. Therefore, I have collected a variety of background information to help me examine the findings of my research study. I wanted to know more about why students struggle with problem solving skills. Phonapichat's (2014) journal explores the results reflecting the inability for students to comprehend mathematical problem solving. His findings include that students had complications understanding and interpreting keywords in the problem. Students were also unable to analyze the problem to identify and distinguish necessary information. Additionally, students did not enjoy the long and lengthy questions. As a result the research studies lead to the development of a math problem-solving diagnostic test for teachers to utilize. However, the article does not state the types of methods created in the diagnostics tests for teachers (Phonapichat, 2014, p. 3171).

I then wanted to explore the specific technological resources that are used to assist students with mathematical problem solving. Zwang (2011), the author of the article of eSchool News, studies the importance for students to gain strong mathematical skills. A mathematical computer program called "Dream Box" delivers hands-on and personalized instruction to help students strengthen these skills. It provides more than 500 elementary level lessons that help students develop skills such as conceptual understanding and problem solving. The program allows students to choose a theme and character making it fun and engaging, while teachers are able to assess their mathematical skills and subsequent advancement (Zwang, 2011 n.p.). 
Another effective software is introduced in Miller’s (2007) article is initiating an electrical software performance system called KidTools. This program contains 30 computerized research based strategy tools that target behavior, academic performance, organization skills, and problem solving. As a result the program promotes cognitive, behavioural, and academic support. It teaches students how to modify a skill in other social contexts which leads to higher problem solving skills (Miller et al., 2007, p. 15). Correspondingly, Deubel (2015) created a website resource called Computing Technology for Math Excellence. This website explains how the collection of mathematical resources for elementary students enrich their math skills. The games and programs are separated into sections such as basic mathematics, skill development, and math proficiency. It initiates problem-solving, critical thinking and standardized testing abilities. It also contains sections that instruct students on how to use devices like iPhone's and tablets. The integration of technology will help students strengthen mathematical skills (Deubel, 2015 n.p.).

Not only are there technological resources to enhance problem solving skills, but also for different learning abilities as well. Babbitt and Miller (1996) use hypermedia to help students with learning disabilities by assisting them with mathematical problem solving skills. Learning strategies that are used to help these students is direct instruction and instructional design that is presented through hypermedia. The hypermedia used is to initiate cognitive strategy to a word problem sequence, thus increasing problem-solving skills. Through direct instruction the aim is for students to understand what is meant by the mathematical problem, such as language and vocabulary (Babbitt \& Miller, 1996, p. 391).

The background information above identifies key components to how digital technology can strengthen problem solving skills. It provides a variety of viewpoints and digital devices that 
strengthens mathematical skills and engage students in the task as well. Jo Boaler’s (2008) novel Whats Math Got to do With it? states, "the reason that mathematicians are successful is that they have learned something very important - and very learnable. They have learned to problem solve” (Boaler, 2008, p. 25), which is exactly what I aim for students to gain through the use of digital technology. Problem solving is a skills that can be learnt and built up over time. The aim is for technology to help assist and strengthen these skills as students learn.

\section{Research Context}

The above background information allowed me to gain interesting insight on how digital technology helped strengthen problem-solving skills. Using what I learned from the background information and my knowledge on what I know about digital technology, it lead me to think about the methods I would use to gather my own research. In my research study, the fundamentals to collecting data were to determine where, who and how I was going to collect my data.

I collected research from 20 participants who were interested in completing my survey. Main participants of my research study were students enrolled in the Bachelor of Education program. Before I conducted my study, I completed the Government of Canada Human Ethics Research Certificate. It was important to ensure that I collected my information from participants over the age of 18, for privacy and security. Collecting information at Mount Royal University, allowed me to gain the perspectives of students and teachers regarding my research topic.

I collected my data through the use of a variety of data collection methods, such as surveys and interviews. Throughout my data collection, I provided an introduction in my survey, explaining the purpose of my survey and addressing that the survey is completely anonymous. It is essential that the participants are protected from harm and that they are not exposed to any 
risks. These fundamentals allowed me to gather significant and useful information for my study. The information collected will be analyzed and interpreted, and will allow me to present my findings meaningfully.

\section{Methods of Investigation}

During my research I conducted an online survey with questions to investigate how digital technology strengthens mathematical problem solving skills. Based on my knowledge of digital technology and problem solving, I had developed various questions to ask my participants using a Google Forms Survey. The questions consisted of a combination of short answer and multiple-choice questions. Once I had gathered my information, I then organized the data through graphs and charts, using Google spreadsheets and word clouds. Organizing my data using these resources, allowed me to analyze and interpret the collected data.

Along with the Google survey, I also interviewed a professional in the Mathematics field, Dr. Pamini Thangarajah. In the interview, I asked questions about her experience with digital technology and problem solving in mathematics. Furthermore, by collecting the information, I was able to further clarify and understand other perspectives regarding my research. This identified how digital technology helped or hindered problem solving, through different point of views.

\section{Findings}

Throughout my interview and using Google Forms I had developed various questions to ask my participants, addressing mathematical problem-solving through the use of digital technologies. My finding section is comprised of pie charts and bar graphs from the online survey. 20 people took part in my survey; of those responses majority of them were post secondary students (see figure 1). I have included six figures in respects to digital technology and 
problem solving.

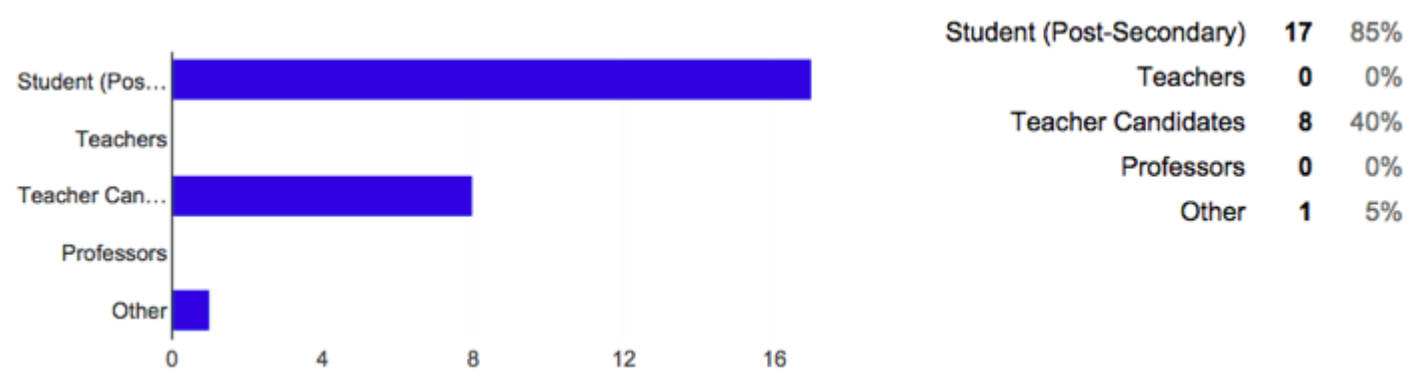

Figure 1. Survey participants’ role.

As I engaged in a conversation with Dr. Pamini Thangarajah, she explained that one of the benefits to digital technology is that it provides accurate mathematical visualizations and uses resources such as Excel and M.A.P.L.E to create them (P.Thangarajah, personal communication, November 10, 2015). I wanted to know what types of digital devices students used for mathematical problem solving as well. In my question, I listed various common device and programs used for mathematics. I also included an other option in case none of the listed devices applied. For this question, the findings showed that Computers and laptops were the most used device for mathematics, followed by phones and Ipods (see figure 2).

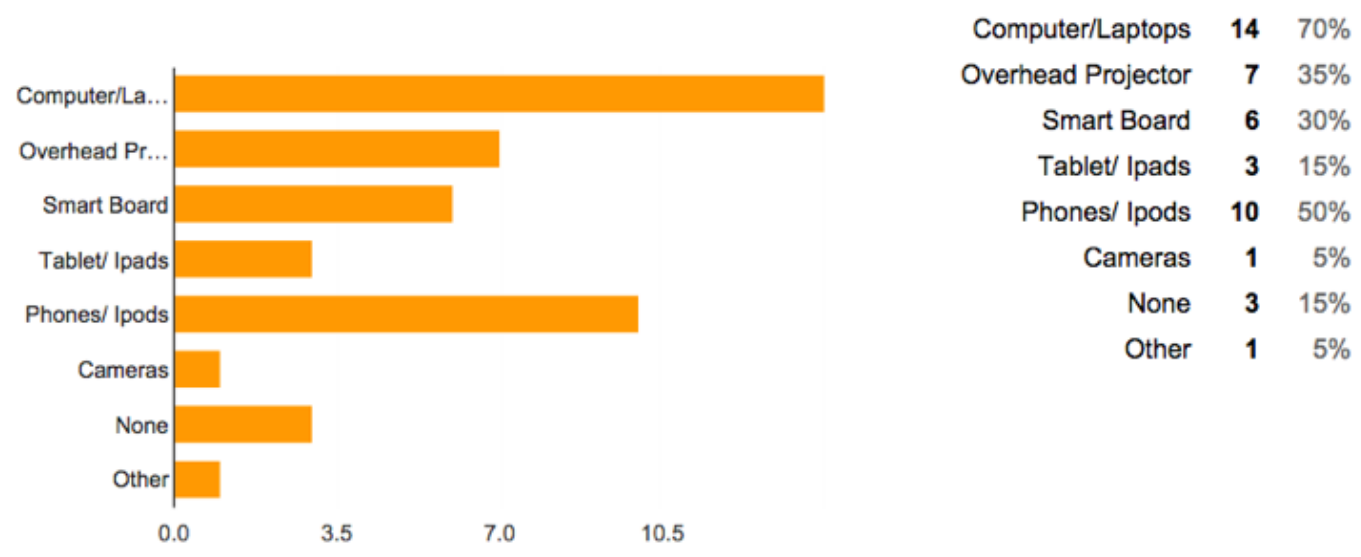

Figure 2. Participants identify the types of technologies they use when problem-solving Mathematical content.

Personally, when it comes to problem solving, I use digital technology as a tool to assist 
me when I am struggling. Therefore, I wanted to know whether my participants used digital technology to help them in mathematics as well. As shown in figure 3, 55\% of the participants said they do use digital technology and 45\% mentioned that they do not use digital technology. The difference between these answers are quite close. This shows me that about 50 percent are on contrary sides of the use of technology in mathematics.

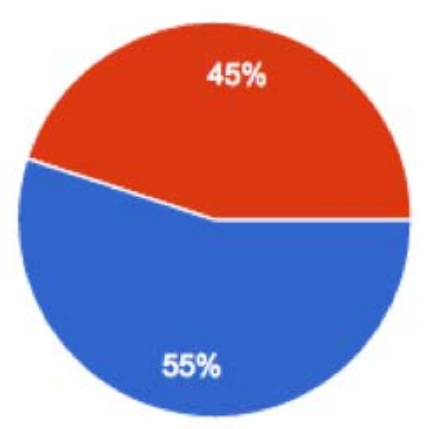

\section{Yes $1155 \%$ \\ No $945 \%$}

Figure 3. Participants identify whether they use digital technology for mathematical problem solving. I then wanted to know whether the participant thought digital technology really helps in mathematics. As shown in figure 4, 84.2\% of the participants said that digital technology does help their understanding of mathematics. It was interesting to see that although, figure 3 showed that about $50 \%$ of the participants used digital technology in mathematics, $84.2 \%$ of them found it beneficial. This finding allows me to determine the benefits of technology regarding mathematics, but specifically for problem solving in mathematics.

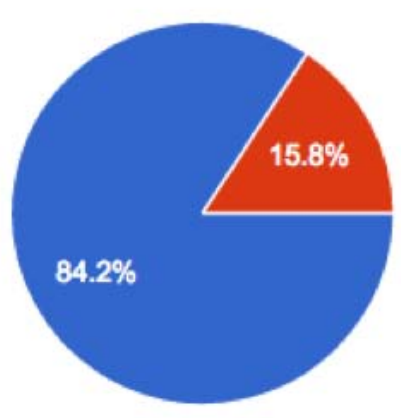

$$
\begin{array}{rrr}
\text { Yes } & \mathbf{1 6} & 84.2 \% \\
\text { No } & \mathbf{3} & 15.8 \%
\end{array}
$$


Figure 4. Participants determine whether digital technologies help assist mathematical problem solving.

The previous information specifies the amount of digital usage of those who use technology for math and those who do not. I wanted to know that if the participants had a choice between using technology or other non-technical resources, which would they rather use. Figure 5 shows a list of common resources that people resort to when they struggle with mathematical problem solving. The findings in figure 5 showed that using an online resource is preferred by $80 \%$ of the participants, followed by asking a professional with $75 \%$, and using a textbook by 60\%. One individual (5\%) mentioned that they would seek help from their peers.

The reason for why I included "give up and not answer the question” was because there are individuals who are discouraged in mathematics and do choose not to answer certain mathematical problem solving questions. I was pleased to see that none of my participants resorted to that answer.

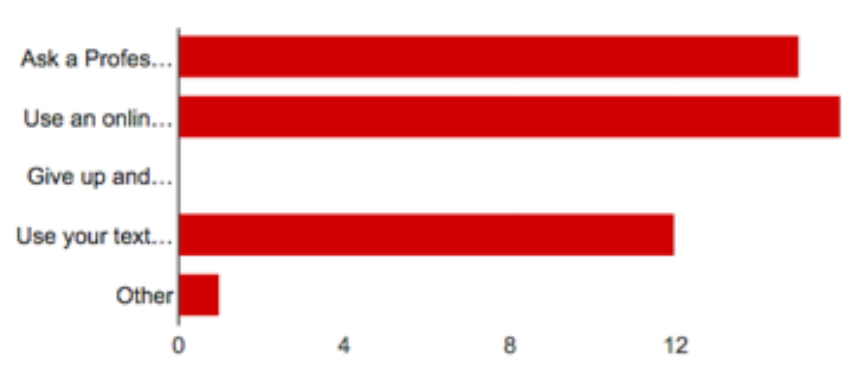

Ask a Professional (teacher, professor, tutor) $15 \quad 75 \%$

Use an online resource. $16 \quad 80 \%$ Give up and not answer the question. $\quad 0 \quad 0 \%$ Use your textbook $12 \quad 60 \%$

Other $15 \%$

Figure 5. Participants identify how they would find an answer to a Mathematical problem they struggle with.

When asked what types of technological resources the participants used, table 1 identifies the participants responses. Participants used resources such as, YouTube videos, Mathletics, Excel, online mind maps, and Google. Many of these resources are common when it comes to math education. 
Table 1.

Identifying the specific technological programs the participants use for Math Education.

\section{Survey Participant Responses}

- Excel works well for Math

- I haven't really used many, but I have heard of one program called Mathletics. I heard it's really good at integrating technology into mathematics.

- Concept maps helps me a lot when brainstorming on the topic. Also, when I did the math project, I always used Microsoft and Google drive to sort my information.

- YouTube (instructional videos)

- I will often look up information on the concepts on the internet if I'm struggling

- Calculators, Google, YouTube videos.

Based on my interview with Dr. Pamini Thangarajah, she explained that when using technology for mathematics, technology is used as a tool to help the process of solving the question. She further explained that technology is "not something [students] should depend on" (P.Thangarajah, personal communication, November 10, 2015). As we engaged further in the conversation, I asked that if technology is not a resource that students should depend on, when should students use technology in math? She replied by explaining that when it comes to mathematics, technology is not very heavily used. If it is, it is used as a "tool , but not as the answer” (P.Thangarajah, personal communication, November 10, 2015). Essentially, in mathematics, it is important to know what the mathematical processes is, and then use what you know through the use of technology. For example, in the Statistics unit it mathematics, programs such as Excel are used as a tool to organize and analyze large amounts of data. However, even when using Excel, one must know the meaning of the information, have knowledge on the content and understand the mathematical vocabulary. Applying what you know using technology will then allow you to effectively organize the gathered statistics and create a better understanding. 
Dr. Thangarajah provided effective feedback on the use of technology in mathematical education. An interesting concept she talked about was the importance of understanding and knowing the mathematics before using technology. Many people resort to technology to give them the answer, rather than as a tool to help them find the answer. Even when using resources such as Google, basic theorems and answers can be found, but in depth mathematical answers to certain questions are rare to find. These findings on mathematical problem solving through the use of technology has provided me with a rich understanding on how technology facilitates mathematical problem solving.

\section{Conclusions and Recommendations}

This research study has allowed me to gather valuable information and insight on how digital technology can strengthen problem-solving skills. As digital technology begins to be used widely in classrooms, I have learned that it has fostered students understanding of mathematics. This is by providing them with accurate visuals and in depth explanations of mathematical vocabulary. Essentially, digital technology is an effective tool for mathematics.

I think that the first step to engaging students in mathematics is to get them to find an interest in it, which I aim to achieve through the use of technology. The studies potential significance for my future teaching practice as an elementary teacher will allow me to engage students in mathematics using technology. I will also be able to utilize certain resources through digital technology to aid their mathematical understanding, especially for students with special needs. From this, students will learn the essential concepts to math, such as problem solving. I believe that learning mathematics is one thing, but being able to problem solve along with it, will results in high levels of critical thinking skills.

My journey through this study not only provided me with answers, but also inspired me 
to inquire more about mathematical problem solving and digital technology. Now that I have understood that digital technology is a tool for math, to what extent should it be used in elementary mathematics? How can us as teachers, prevent students from relying on digital technology? Is digital technology giving students the answer rather than aiding their understanding of math? Further research can be conducted to address these questions, through interviews, broad surveys and from my future experience as an elementary teacher as well.

\section{References}

Babbitt, B.C., \& Miller, S.P. (1996). Using hypermedia to improve mathematical problemsolving skills of students with learning disabilities. Journal of Learning Disabilities, 29(4), 390 -391. Retrieved from http://goo.gl/CEDtCV

Boaler, J. (2008). What's Math Got To Do With It?: Helping children learn to love their least favorite subject - and why it's important for America. New York: Penguin Group.

Deubel, P. (2015, May 18). Math resources: elementary and middle school: basic mathematics and skills development plus apps for mobile devices. Retrieved October 1, 2015, from http://www.ct4me.net/math_resources.htm

Miller, K.J., Fitzgerald, G.E., Koury, K.A., Mitchem, K.J., \& Hollingsead, C. (2007). KidTools: Self-management, problem solving, organization, and planning software for children and teachers. Intervention in Schools and Clinic, 43(1), 8-12. Retrieved from http://goo.gl/MaQiZE

Phonapichat, P. (2014) An analysis of elementary school students’ difficulties in mathematical problem solving. Procedia - Social Behavioral Sciences, 116, 3169 - 3174. doi:10.1016/j.sbspro.2014.01.728

Zwang, J. (2011, March 14). Software helps personalize math instruction. eSchool News. 
Retrieved from http://www.eschoolnews.com/2011/03/14/software-helps-personalizemath-instruction/ 